\title{
Taze Dışkı Örneklerinde Direkt Mikroskobik İncelemede Alternatif Yaklaşımlar
}

\section{Alternative Approaches in Direct Microscobic Examination of Fresh Fecal Samples}

\author{
Koray ÖNCEL ${ }^{1}$ \\ ${ }^{1}$ Mehmet Akif İnan Eğitim ve Araştırma Hastanesi, Mikrobiyoloji Laboratuvarı, Şanlıurfa. \\ ${ }^{1}$ Mehmet Akif inan Training and Research Hospital, Microbiology Laboratory, Şanlıurfa, Turkey.
}

* Bu çalışma, Uluslararası 21. Parazitoloji Kongresi (28 Eylül-3 Ekim 2019, İzmir)'nde bildiri olarak sunulmuştur.

\section{ÖZ}

Bu çalışmada, taze dışkı örneklerinde, ıslak preparat (nativ-lugol) incelemesinde tanımlamada zorlandığımız protozoonların farkı fiksatifler kullanılarak modifiye edilmiş trikrom boyası ile yaklaşık beş dakika içinde tanımlanması amaçlanmıştır. Alternatif yaklaşımda kullanılmak üzere iki farklı fiksatif hazırlanmışır. Mordan [bazı boyalar ile koordinasyon kompleksleri oluşturan polivalan (en az +2 değerlikli) metaller] olarak bakır sülfat pentahidrat $\left(\mathrm{CuSO}_{4} \cdot 5 \mathrm{H}_{2} \mathrm{O}\right)$ kullanılarak hazırlanmış olan fiksatiflerden bir tanesi (fiksatif- 1 ) etil alkol, formalin, asetik asit, distile su bazlı olup, diğeri (fiksatif-2) ise etil alkol, formalin, sitrik asit, distile su bazlı olarak hazırlanmışıır. îki ayrı fiksatif ile de tespit edilmiş preparatlar Gomori'nin trikrom boyasının tarafımızca modifiye edilmiş şekli ile boyanmıştır. Kontrol ve kıyaslama amacıyla altın standart olarak; cıva klorür içeren Schaudinn fiksatifi ile fikse edilen örnekler Gomori'nin trikrom boyasının Wheatley modifikasyonu ile boyanmıştır. Taze dışkı örneklerinde nativ-lugol inceleme yapıldıktan sonra, insan bağırsak protozoonu içerdiği düşünülen 50 adet dışkı örneği üzerinde çalışıııışır. Yöntemler kıyaslandığında, sitrik asit içeren yöntem ile hazırlanan preparatlar (Entamoeba coli kistleri içerenler dışında) klasik yöntem kullanılarak hazırlanan preparatlara hemen hemen yakın sonuçlar verirken, asetik asit içeren yöntem ile hazırlanan preparatlar klasik yönteme göre Entamoeba coli kistleri içerenlerde çok net olmak üzere Blastocystis spp., Endolimax nana, lodamoeba bütschlii ve Entamoeba hartmanni içeren preparatlarda daha düşük bir performans sergilemiş̧ir. Klasik yönteme kıyasla her iki yeni fiksatifte Dientamoeba fragilis içeren preparatlarda daha üstün bir performans sergilerken, süreç açısından da yaklaşık on katlık bir zaman avantajı sağlamışır. Her iki alternatif yöntem kendi aralarında kıyaslandığında ise, fiksatif-2 ile hazırlanan preparatlar Blastocystis spp., E.nana, I.bütschlii ve E.hartmanni açısından kıstas alınan kriterler bazında daha iyi performans sergilerken, fiksatif-1 D.fragilis içeren preparatlarda minimal bir üstünlük sergilemiştir. Çalışmamızda kullanmış olduğumuz fiksatif-2 ve modifiye edilmiş boyama yöntemi parazitoloji ve mikrobiyoloji laboratuvarlarında yapılmakta olan insan dışkısına ait parazitolojik tetkiklerde boya ile tanımlama sürecinde E.coli kistleri içerenler dışında klasik yönteme kıyasla on kat daha hızlı tanıya ulaşımasına olanak sağlamaktadır. Bu yöntemin rutin mikrobiyolojik tanıda klasik yönteme iyi bir alternatif olabileceği düşünülmüştür.

Anahtar kelimeler: Protozoon; dışkı; fiksatif; trikrom boyama. 


\section{ABSTRACT}

Aim of the present study was to identify protozoones which are difficult to define through wet slide in fresh fecal samples by using different fixatives with modified Trichrome stain within five minutes. Two different fixatives prepared for the alternative approach. The slides were fixed by two different fixatives, one of them (fixative-1) was based ethylalcohol, formalin, acetic acid, distilled water and the other one (fixative-2) based ethylalcohol, formalin, citric acid, distilled water included a mordant [divalent or polyvalent metals which make coordination complex with some dyes] consisted copper sulphate pentahydrate $\left(\mathrm{CuSO}_{4} \cdot 5 \mathrm{H}_{2} \mathrm{O}\right)$. Slides prepared by the two different fixatives were stained by a different modification of Gomori's trichrome stain that we made. Samples fixed by Schaudinn fixative including mercury chloride were stained by Wheatley modification of Gomori's trichrome stain as a gold standard for control and comparison. We worked with 50 fecal samples which we thought included human intestinal protozoones after the wet slide examination. Comparing the methods, slides prepared with the method including citric acid gave almost similar results with the classical method excluded Entamoeba coli cystes. Slides prepared with the methode including acetic acid gave low performance compared with the classical method especially E.coli cystes and Blastocystis spp., Endolimax nana, lodamoeba bütschlii, E.hartmanni. Both new fixatives gave superior performance at the slides included Dientamoeba fragilis and approximately shorten the procedure process ten times than the classical method. When the both alternative methods compared in each other, the slides prepared with fixative- 2 exposed better performance for the protozoones Blastocystis spp., E.nana, I.bütschlii and E.hartmanni while the fixative-1 displayed minimal superiority for $D$.fragilis including criterias that we based. The fixative- 2 and modified stain methode that we used in our study, makes available the diagnostic phase ten times faster than the classical method in human stool parasitological tests excluding the E.coli cystes at parasitology and microbiolgy laboratories. It seems to be a good option to the classical method for routine usage.

Keywords: Protozoa; feces; fixative; trichrome staining.

\section{Giriş}

Dışkı örneklerinde bağırsak parazitlerinin tanısını etkileyen en önemli faktörlerden biri de numunenin verilişi ile incelenmesi arasında geçen zaman faktörüdür. İdeal şartlarda sulu ve yarı katı dışkılarda özellikle de trofozoit şekillerinin yapılarının bozulmadan tanımlanabilmesi için numune verildikten 30 dakika içinde incelenmesi gerekmektedir. Sürecin aşılması ile saatler içinde ısı ve nem kaybına bağlı olarak trofozoitler varsa kistik formlarına dönüşmekte ya da otolize uğramaktadırlar. Hasta-çalışan uyumu, laboratuvar işleyiş yoğunluğu, ilk incelemede tanımlamada tereddütte kalınan numunelerin tekrardan incelenmesi gibi faktörler bu sürecin aksamasına neden olmaktadır. Zaman faktörünü bir şekilde bertaraf edebilmek için fiksatifler kullanılmaktadır ${ }^{1,2}$.

Dışkı örneklerinin fiksasyonu ve boyanması, parazitlerin iç yapılarının açıkça izlenmesini ve doğru şekilde tanımlanmalarını sağlamaktadır ${ }^{3}$.

Uzun yıllardan beri laboratuvar çalışanları için potansiyel tehlike arz etmesine rağmen, formalin çözeltisi, cıva klorür $\left(\mathrm{HgCl}_{2}\right)$ bazlı Schaudinn çözeltisi ve düşük viskoziteli polivinilalkol (PVA) fiksatifleri bağırsak parazitlerini tanımlamak için insan dışkı örneklerini korumada çoğu kamusal, özel ve ticari laboratuvarda yaygın bir şekilde kullanılmaktadır ${ }^{4-8}$.

Formalin ve PVA halen bağırsak parazitlerinin uzun süreli korunmasında altın standart kabul edilmekteyken, bağırsak parazitleri olarak özellikle protozoonlardan kalıcı preparatlar hazırlamada örneklerin Schaudinn ya da PVA'da fikse edilmesi en önemli teknik olarak düşünülmektedir ${ }^{5-8}$. 
Formaldehit içeriği \%5-10 oranında olan formalin çözeltisi helmintleri, helmint yumurtalarını ve protozoon kistlerini koruma amaçlı kullanılan çok yönlü bir fiksatiftir. Potansiyel karsinojenik özellikleri, inhalasyon ve ciltten emilimi sonrasındaki yüksek toksisitesi sebebiyle çalışma ortamında ciddi güvenlik kaygıları oluşturmaktadır. Formalinin çamaşır suyu kullanılarak nötralizasyonu sonrası sıvı atık olarak atılması hem elverişsiz hem de külfetli olup uzun süre gerektirmektedir ${ }^{8,9}$.

PVA Schaudinn fiksatifi içinde çözünen plastik bir reçine olup; dışkı yaymaları hazırlanması esnasında dışkının cam preparat üzerine yapışmasını kolaylaştırıcı etki yapmaktadır. PVA'lı ya da PVA'sız Schaudinn fiksatifleri potansiyel karsinojen, yüksek toksik ve koroziv etki gösteren cıva klorür içermektedir. Cıva ısıya maruz kaldığında yüksek miktarda toksik buhar oluşturmakta, oluşan buhar cilt ve mukoz membranlar tarafından absorbe edilmekte ve kronik cıva zehirlenmesine yol açmaktadır. Bertarafı oldukça pahalı ve çok fazla işlem gerektirmektedir $3,6,8,9$.

Bu çalışma, taze dışkı örneklerinde, ıslak preparat (nativ-lugol) incelemesinde tanımlamada zorlandığımız protozoonların farklı fiksatifler kullanılarak modifiye edilmiş trikrom boyası ile yaklaşık beş dakika içinde tanımlanmasını ve elde edilen bulguların altın standart olarak kabul edilen Schaudinn ile fikse edilerek trikrom boyama yöntemi ile kıyaslanmasını amaçlamaktadır.

\section{GEREÇ ve YÖNTEM}

Bu çalışma, Harran Üniversitesi Tıp Fakültesi Etik Kurulu onayı ile gerçekleştirildi (Tarih: 02.08.2018 ve Karar no: 22).

Çalışmamızda kullanılan fiksatiflerimizden biri, Öncel'in daha önceki bir çalışmasında ${ }^{2}$ uygulamış olduğu içerik ile aynı olup 100 ml'de; $15 \mathrm{ml}$ etil alkol (\%96 oranında etil alkol), $1 \mathrm{ml}$ formalin çözeltisi (\%37-40 oranında formalin), $5 \mathrm{ml}$ asetik asit (\%99 oranında asetik asit) ve $79 \mathrm{ml}$ distile su içerecek şekilde hazırlandı. Bu çözelti fiksatif-1 olarak adlandırıldı.

Diğer fiksatif ise içerik olarak $100 \mathrm{ml}$ 'de; $15 \mathrm{ml}$ etil alkol (\%96 oranında etil alkol), $1 \mathrm{ml}$ formalin çözeltisi (\%37-40 oranında formalin), $250 \mathrm{mg}$ sitrik asit (\%99 oranında sitrik asit) ve $84 \mathrm{ml}$ distile su içerecek şekilde hazırlandı. Bu çözelti fiksatif-2 olarak adlandırıldı.

Hazırladığımız baz fiksatif çözeltilerinin içerisine mordan olarak; 50 mg bakır sülfat pentahidrat $\left(\mathrm{CuSO}_{4} .5 \mathrm{H}_{2} \mathrm{O}\right)$ eklenip karıştırılarak tamamen fiksatifler içinde çözünmeleri sağlandı. Mordanlar çözüldüğü anda iki farklı fiksatif de kullanıma hazır hale getirildi.

Karşılaştırma amacıyla altın standart yöntem olarak cıva klorür $\left(\mathrm{HgCl}_{2}\right)$ içeren Schaudinn fiksatifi kullanıldı.

Taze dışkı örnekleri nativ-lugol inceleme yapıldıktan sonra, insan bağırsak protozoonu içerdiği düşünülen 50 adet dışkı örneği üzerinde çalışıldı. Fiksasyon ve boyama süreçleri eşzamanlı olarak gerçekleştirildi. 
Altın standart yöntem ile fikse edilen ve Gomori'nin trikrom boyasının Wheatley modifikasyonu ile boyanan preparatlar yaklaşık 60-70 dakika arasında incelemeye hazır hale getirildi. Bu yöntem klasik yöntem olarak adlandırıldı ${ }^{10}$. Her iki alternatif yöntemde de örnekler; fiksatifte bir dakika, \%96 oranındaki etil alkolde üç dakika, trikrom boyada bir dakika bekletildi. Renk giderme aşamasında fiksatif- 1 ile fikse edilen örnekler sırasıyla 0.5 $\mathrm{ml}$ glasiyal asetik asit içeren \%90'lık etil alkolde 1-3 saniye, sonrasında iki adet \%96'lık etil alkolde 1-3 saniye, fiksatif-2 ile fikse edilenler ise $25 \mathrm{mg}$ sitrik asit içeren \%90'lık etil alkolde 1-3 saniye, sonrasında iki adet \%96'lık etil alkolde 1-3 saniye bekletilerek boyama işlemi tamamlandı. Ksilende bir dakika yeterli olmakla birlikte süreyi uzatıp uzatmamak uygulayıcının karar verme yetkisine bırakıldı.

Her dışkı örneği için hazırlanan üçer adet boyalı preparat x1000 büyütmede ışık mikroskobunda incelendi. Değerlendirme sırasında dikkat edilen parametreler; genel anlamda parazitin morfolojisi, çekirdek ve sitoplazmik organellere ait detayların şekil ve netliği ile parazitin dışkıdaki artefaktların arasında fark edilebilirliği şeklinde belirlendi. Skorlamada bu kriterler dikkate alındığında; 1 değeri en kötü, 5 değeri ise en iyi kriterlere sahip olanı belirtmek için kullanıldı.

\section{BULGULAR}

Nativ-lugol inceleme sonrası insan bağırsak protozonu olduğu düşünülen 50 adet taze dışkı örneğine ait toplamda 150 adet boyalı preparat incelenmiş ve kullanılan fiksatiflere göre bulgular Tablo I'de kıyaslanmıştır.

Blastocystis spp. içeren preparatlar ele alındığında, fiksatif-2 ile klasik yöntemin benzer etkinlikte olduğu ve fiksatif-1'e kıyasla parazitin morfolojik netliği ile parazitin dışkıdaki artefaktların arasında fark edilebilirliği açısından daha üstün olduğu gözlenmiştir (Resim 1a,b,c).

Dientamoeba fragilis içeren preparatlar ele alındığında, fiksatif-1 ile fiksatif-2'nin benzer etkinlikte olduğu ve klasik yönteme kıyasla parazitin morfolojik netliği ile parazitin dışkıdaki artefaktların arasında fark edilebilirliği açısından daha üstün olduğu gözlenmiştir. Alternatif fiksatifler kendi içinde kıyaslandığında, fiksatif-1'in parazitin çekirdek morfolojisinin netliği ve fark edilebilirliği açısından fiksatif-2'den bir miktar üstün olduğu görülmüş̧ür (Resim 2a,b,c).

Endolimax nana içeren preparatlar ele alındığında, parazitin morfolojik netliği ile parazitin dışkıdaki artefaktların arasında fark edilebilirliği açısından sırasıyla en üstün fiksatif-2, sonrasında klasik yöntem, en son olarak da fiksatif-1 olduğu gözlenmiştir. İncelenen preparatların \%90'ında parazitin trofozoit formları görülmüştür. Kist formları açısından her üç yöntem açısından belirgin bir farklılık olmamasına rağmen, trofozoit formlarında özellikle fiksatif-1 ile yapılan preparatlarda parazitin sitoplazmasının ve çekirdeğinin diğer yöntemlerdekine kıyasla daha soluk boyandığı, morfolojik netliği ile parazitin dışkıdaki artefaktların arasında fark edilebilirliğinin düşük olduğu gözlenmiştir (Resim $3 a, b, c, d, e, f)$. 


\begin{tabular}{|c|c|c|c|c|}
\hline \multirow[b]{3}{*}{ Örnek no } & \multirow[b]{3}{*}{ Parazit } & \multicolumn{3}{|c|}{ Kullanılan fiksatif ve içerdiği mordan } \\
\hline & & \multicolumn{2}{|c|}{ Yeni fiksatif } & \multirow{2}{*}{$\begin{array}{c}\text { Schaudinn } \\
\mathrm{HgCl}_{2}\end{array}$} \\
\hline & & Fiksatif-1 & Fiksatif-2 & \\
\hline 1 & $\begin{array}{l}\text { B.hominis } \\
\text { E.nana (trf) }\end{array}$ & $\begin{array}{l}2,3 \\
2,3\end{array}$ & $\begin{array}{l}3,4 \\
4,5\end{array}$ & $\begin{array}{c}3 \\
3,4\end{array}$ \\
\hline 2 & $\begin{array}{l}\text { B.hominis } \\
\text { E.nana (trf) }\end{array}$ & $\begin{array}{l}3-5 \\
3,4\end{array}$ & $\begin{array}{l}4,5 \\
4,5\end{array}$ & $\begin{array}{l}3,4 \\
2-4\end{array}$ \\
\hline 3 & B.hominis & 3 & 4,5 & 4 \\
\hline 4 & $\begin{array}{l}\text { B.hominis } \\
\text { E.hominis (trf) }\end{array}$ & $\begin{array}{l}3-5 \\
3-5\end{array}$ & $\begin{array}{l}4,5 \\
4,5\end{array}$ & $\begin{array}{l}3,4 \\
2,3\end{array}$ \\
\hline 5 & B.hominis & 2,3 & 4,5 & $3-5$ \\
\hline 6 & $\begin{array}{l}\text { B.hominis } \\
\text { E.hominis (trf) }\end{array}$ & $\begin{array}{l}2-4 \\
1-3\end{array}$ & $\begin{array}{l}3,4 \\
2-5\end{array}$ & $\begin{array}{l}3-5 \\
1,2\end{array}$ \\
\hline 7 & $\begin{array}{l}\text { I.bütschlii (k) } \\
\text { C.mesnili (k) }\end{array}$ & $\begin{array}{l}1-4 \\
1-4\end{array}$ & $\begin{array}{l}2-4 \\
2-4\end{array}$ & $\begin{array}{c}4,5 \\
3\end{array}$ \\
\hline 8 & $\begin{array}{l}\text { B.hominis } \\
\text { E.nana (trf) }\end{array}$ & $\begin{array}{l}1,2 \\
1,2\end{array}$ & $\begin{array}{l}3-5 \\
3-5\end{array}$ & $\begin{array}{l}3-5 \\
3-5\end{array}$ \\
\hline 9 & I.bütschlii (k) & $1-3$ & $1-5$ & 4,5 \\
\hline 10 & B.hominis & $2-4$ & 4,5 & 3 \\
\hline 11 & $\begin{array}{l}\text { E.nana (trf) } \\
\text { E.coli (k) }\end{array}$ & $\begin{array}{l}4,5 \\
1,2\end{array}$ & $\begin{array}{c}5 \\
1,2\end{array}$ & $\begin{array}{c}5 \\
4,5\end{array}$ \\
\hline 12 & E.hartmanni (k) & $1-4$ & $2-4$ & 4,5 \\
\hline 13 & $\begin{array}{l}\text { I.bütschlii (k) } \\
\text { E.coli (k) }\end{array}$ & $\begin{array}{l}1-4 \\
1,2\end{array}$ & $\begin{array}{c}1-4 \\
1\end{array}$ & $\begin{array}{l}3-5 \\
3,4\end{array}$ \\
\hline 14 & G.intestinalis (k) & $1-5$ & $1-5$ & $3-5$ \\
\hline 15 & D.fragilis & $3-5$ & $3-5$ & $2-5$ \\
\hline 16 & G.intestinalis (k) & 4,5 & $3-5$ & $3-5$ \\
\hline 17 & B.hominis & 4,5 & 4,5 & 1,2 \\
\hline 18 & G.intestinalis (k) & $1-5$ & $1-5$ & $2-5$ \\
\hline 19 & E.hominis (k) & $1-4$ & $1-5$ & 4,5 \\
\hline 20 & $\begin{array}{l}\text { B.hominis } \\
\text { E.nana (trf) }\end{array}$ & $\begin{array}{l}1-4 \\
2-5\end{array}$ & $\begin{array}{l}2-5 \\
4,5\end{array}$ & $\begin{array}{l}4,5 \\
3-5\end{array}$ \\
\hline 21 & $\begin{array}{l}\text { B.hominis } \\
\text { E.nana (k) }\end{array}$ & $\begin{array}{l}1-4 \\
1-4\end{array}$ & $\begin{array}{l}4,5 \\
4,5\end{array}$ & $\begin{array}{c}3 \\
4,5\end{array}$ \\
\hline 22 & G.intestinalis (k) & $1-5$ & $1-5$ & $2-5$ \\
\hline 23 & E.coli (k) & 1,2 & 1,2 & $1-5$ \\
\hline 24 & D.fragilis & $2-5$ & $3-5$ & 1,2 \\
\hline 25 & $\begin{array}{l}\text { B.hominis } \\
\text { E.nana (trf) }\end{array}$ & $\begin{array}{l}1-3 \\
3,4\end{array}$ & $\begin{array}{c}1-3 \\
5\end{array}$ & $\begin{array}{l}4,5 \\
4,5\end{array}$ \\
\hline 26 & $\begin{array}{l}\text { B.hominis } \\
\text { E.coli (k) }\end{array}$ & $\begin{array}{c}1 \\
1,2\end{array}$ & $\begin{array}{c}1,2 \\
1\end{array}$ & $\begin{array}{l}4,5 \\
4,5\end{array}$ \\
\hline
\end{tabular}




\begin{tabular}{|c|c|c|c|c|}
\hline \multirow[b]{3}{*}{ Örnek no } & \multirow[b]{3}{*}{ Parazit } & \multicolumn{3}{|c|}{ Kullanılan fiksatif ve içerdiği mordan } \\
\hline & & \multicolumn{2}{|c|}{ Yeni fiksatif } & \multirow{2}{*}{$\begin{array}{c}\text { Schaudinr } \\
\mathrm{HgCl}_{2}\end{array}$} \\
\hline & & Fiksatif-1 & Fiksatif-2 & \\
\hline 27 & $\begin{array}{l}\text { B.hominis } \\
\text { G.intestinalis (k) }\end{array}$ & $\begin{array}{l}1-3 \\
2-5\end{array}$ & $\begin{array}{l}1-4 \\
3-5\end{array}$ & $\begin{array}{l}4,5 \\
4,5\end{array}$ \\
\hline 28 & $\begin{array}{l}\text { B.hominis } \\
\text { D.fragilis }\end{array}$ & $\begin{array}{l}2-4 \\
1-4\end{array}$ & $\begin{array}{l}3-5 \\
3,4\end{array}$ & $\begin{array}{l}4,5 \\
1,2\end{array}$ \\
\hline 29 & $\begin{array}{l}\text { E.hartmanni (k) } \\
\text { E.nana (trf) }\end{array}$ & $\begin{array}{l}1,2 \\
1,2\end{array}$ & $\begin{array}{l}1-3 \\
1-4\end{array}$ & $\begin{array}{l}1-5 \\
1,2\end{array}$ \\
\hline 30 & $\begin{array}{l}\text { I.bütschlii (k) } \\
\text { E.hartmanni (k) } \\
\text { E.coli }(\mathrm{k})\end{array}$ & $\begin{array}{c}1,2 \\
1 \\
1,2\end{array}$ & $\begin{array}{l}4,5 \\
1-4 \\
1,2\end{array}$ & $\begin{array}{l}3-5 \\
2-5 \\
1-5\end{array}$ \\
\hline 31 & $\begin{array}{l}\text { B.hominis } \\
\text { E.coli }(\mathrm{pk}) \\
\text { E.coli }(\mathrm{k})\end{array}$ & $\begin{array}{l}3-5 \\
4,5 \\
1,2\end{array}$ & $\begin{array}{l}4,5 \\
4,5 \\
1,2\end{array}$ & $\begin{array}{c}4,5 \\
5 \\
1-5\end{array}$ \\
\hline 32 & $\begin{array}{l}\text { B.hominis } \\
\text { D.fragilis } \\
\text { E.coli (trf) } \\
\text { E.coli (k) }\end{array}$ & $\begin{array}{l}2-4 \\
3-5 \\
4,5 \\
2,3\end{array}$ & $\begin{array}{c}3-5 \\
3-5 \\
4,5 \\
3\end{array}$ & $\begin{array}{c}4,5 \\
1,2 \\
4,5 \\
5\end{array}$ \\
\hline 33 & $\begin{array}{l}\text { B.hominis } \\
\text { G.intestinalis (k) }\end{array}$ & $\begin{array}{l}1-3 \\
1-4\end{array}$ & $\begin{array}{l}1-4 \\
1-3\end{array}$ & $\begin{array}{c}3 \\
3-5\end{array}$ \\
\hline 34 & E.coli (k) & $1-4$ & $1-4$ & $1-4$ \\
\hline 35 & $\begin{array}{l}\text { B.hominis } \\
\text { D.fragilis } \\
\text { E.coli (trf) } \\
\text { E.coli (pk) } \\
\text { E.coli (k) }\end{array}$ & $\begin{array}{c}1-3 \\
3-5 \\
4,5 \\
4,5 \\
2\end{array}$ & $\begin{array}{l}2-4 \\
3-5 \\
4,5 \\
4,5 \\
1,2\end{array}$ & $\begin{array}{c}4,5 \\
2,3 \\
5 \\
5 \\
4,5\end{array}$ \\
\hline 36 & $\begin{array}{l}\text { C.mesnili (trf) } \\
\text { C.mesnili (k) } \\
\text { B.hominis } \\
\text { E.coli (pk) } \\
\text { E.coli }(\mathrm{k})\end{array}$ & $\begin{array}{c}4,5 \\
2-4 \\
2-4 \\
4,5 \\
1\end{array}$ & $\begin{array}{c}4,5 \\
1-4 \\
3-5 \\
4,5 \\
1\end{array}$ & $\begin{array}{c}2-4 \\
2-4 \\
2-4 \\
5 \\
4\end{array}$ \\
\hline 37 & $\begin{array}{l}\text { B.hominis } \\
\text { C.mesnili (k) }\end{array}$ & $\begin{array}{l}2-5 \\
3-5\end{array}$ & $\begin{array}{r}4,5 \\
3-5\end{array}$ & $\begin{array}{l}2-5 \\
3-5\end{array}$ \\
\hline 38 & C.mesnili(k) & $3-5$ & $2-5$ & $3-5$ \\
\hline 39 & $\begin{array}{l}\text { D.fragilis } \\
\text { E.coli }(\mathrm{k})\end{array}$ & $\begin{array}{l}4,5 \\
1,2\end{array}$ & $\begin{array}{l}3-5 \\
1-3\end{array}$ & $\begin{array}{c}1 \\
4,5\end{array}$ \\
\hline 40 & I.bütschlii (k) & $1-4$ & $2-5$ & 4,5 \\
\hline 41 & E.hartmanni $(\mathrm{k})$ & $1-3$ & $1-4$ & $3-5$ \\
\hline 42 & $\begin{array}{l}\text { B.hominis } \\
\text { D.fragilis }\end{array}$ & $\begin{array}{l}1-4 \\
3-5\end{array}$ & $\begin{array}{l}2-5 \\
2-5\end{array}$ & $\begin{array}{l}1-4 \\
1-3\end{array}$ \\
\hline 43 & $\begin{array}{l}\text { B.hominis } \\
\text { G.intestinalis (k) }\end{array}$ & $\begin{array}{l}2-4 \\
3-5\end{array}$ & $\begin{array}{r}2,3 \\
3-5\end{array}$ & $\begin{array}{l}3-5 \\
3-5\end{array}$ \\
\hline 44 & I.bütschlii (k) & $1-4$ & 4,5 & 3,4 \\
\hline
\end{tabular}




\begin{tabular}{|c|c|c|c|c|}
\hline \multirow[b]{3}{*}{ Örnek no } & \multirow[b]{3}{*}{ Parazit } & \multicolumn{3}{|c|}{ Kullanılan fiksatif ve içerdiği mordan } \\
\hline & & \multicolumn{2}{|c|}{ Yeni fiksatif } & \multirow{2}{*}{$\begin{array}{c}\text { Schaudinn } \\
\mathrm{HgCl}_{2}\end{array}$} \\
\hline & & Fiksatif-1 & Fiksatif-2 & \\
\hline \multirow{3}{*}{45} & C.mesnili (trf) & 4,5 & 4,5 & 4 \\
\hline & C.mesnili (k) & $2-5$ & $3-5$ & $3-5$ \\
\hline & B.hominis & $1-4$ & $2-4$ & 3,4 \\
\hline \multirow[t]{3}{*}{46} & B.hominis & $1-4$ & $2-4$ & 4 \\
\hline & E.hartmanni (trf) & $2-4$ & $3-5$ & $3-5$ \\
\hline & E.hartmanni (pk) & 3,4 & 4,5 & 4 \\
\hline \multirow[t]{4}{*}{47} & B.hominis & $2-4$ & $2-4$ & $2-4$ \\
\hline & D.fragilis & $3-5$ & $2-5$ & 2 \\
\hline & E.hartmanni (trf) & 4,5 & $3-5$ & 4,5 \\
\hline & E.hartmanni (pk) & 5 & 4,5 & 5 \\
\hline 48 & E.nana (trf) & $1-3$ & 4,5 & $3-5$ \\
\hline 49 & D.fragilis & 4,5 & 3,4 & 1,2 \\
\hline \multirow[t]{4}{*}{50} & C.mesnili (k) & $1-4$ & $2-4$ & $2-4$ \\
\hline & E.hartmanni (trf) & $1-4$ & $1-4$ & $3-5$ \\
\hline & E.hartmanni (pk) & $1-4$ & 4,5 & 4,5 \\
\hline & E.hartmanni (k) & 1 & $1-5$ & $3-5$ \\
\hline
\end{tabular}

trf: Trofozoit, pk: Prekist, k: Kist.

1-5 arası rakamlar: Değerlendirme esnasında dikkat edilen parametrelerin (genel anlamda parazitin morfolojisi, çekirdek ve sitoplazmik organellere ait detayların şekil ve netliği ile parazitin dışkıdaki artefaktların arasında fark edilebilirliği) incelemeyi yapan uzman tarafından sayısal verilere dökümüdür. 1 değeri en kötü, 5 değeri en iyi sayısal veriye karşılık gelmektedir.
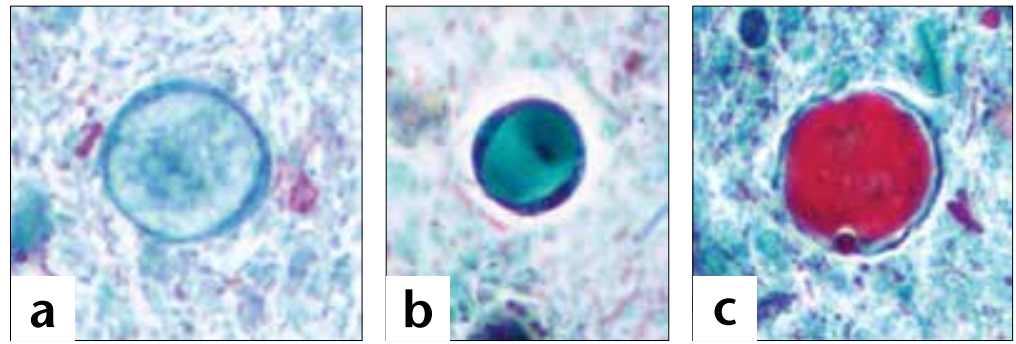

Resim 1. a. Fiksatif-1, B.hominis, b. Fiksatif-2, B.hominis, c. Schaudinn fiksatifi, B.hominis.
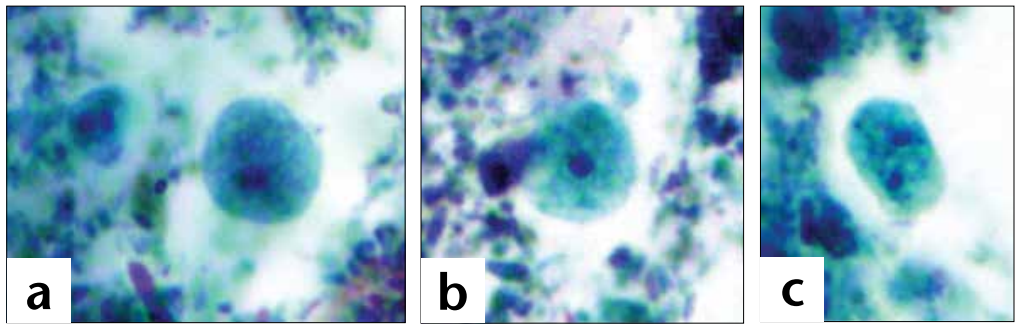

Resim 2. a. Fiksatif-1, D.fragilis, b. Fiksatif-2, D.fragilis, c. Schaudinn fiksatifi, D.fragilis. 

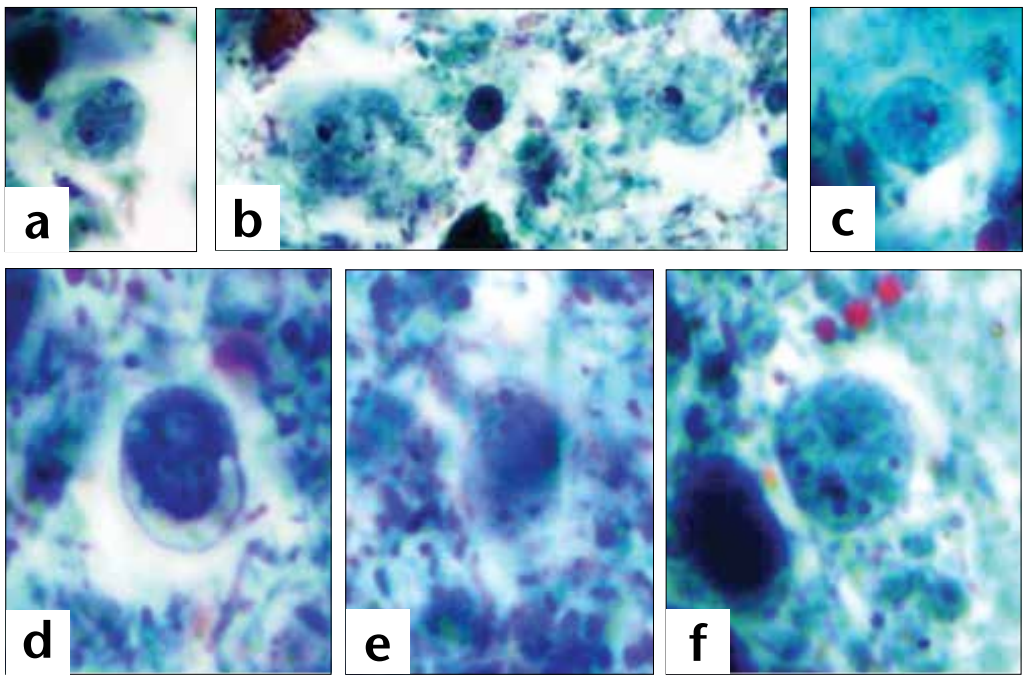

Resim 3. a. Fiksatif-1, E.nana (trofozoit), b. Fiksatif-2, E.nana (trofozoit), c. Schaudinn fiksatifi, E.nana (trofozoit), d. Fiksatif-1, E.nana (kist), e. Fiksatif-2, E.nana (kist), f. Schaudinn fiksatifi, E.nana (kist).
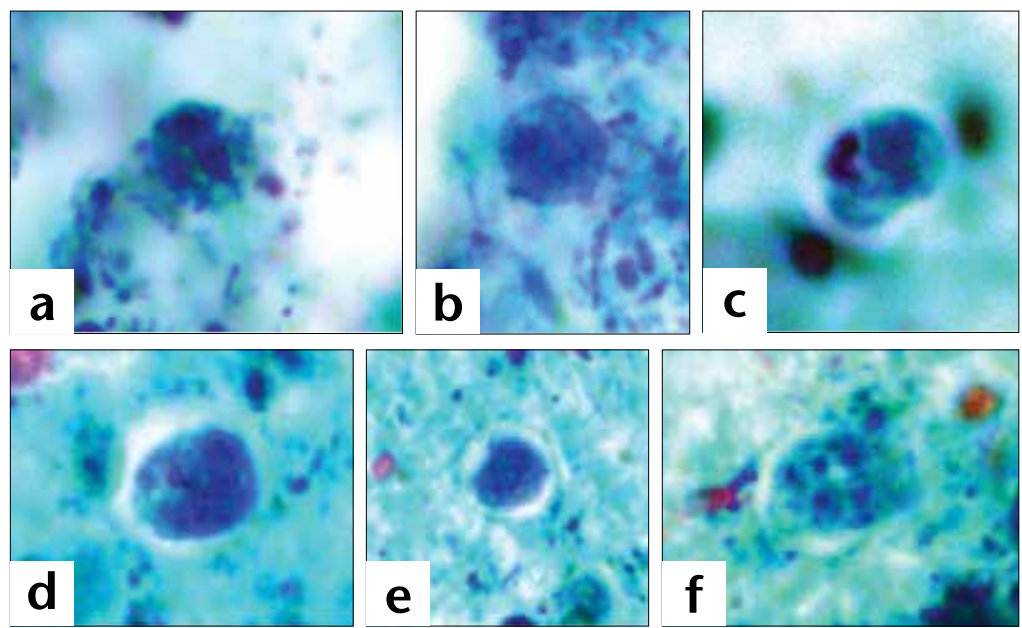

Resim 4. a. Fiksatif-1, E.hominis (trofozoit), b. Fiksatif-2, E.hominis (trofozoit), c. Schaudinn fiksatifi, E.hominis (trofozoit), d. Fiksatif-1, E.hominis (kist), e. Fiksatif-2, E.hominis (kist), f. Schaudinn fiksatifi, E.hominis (kist).

Enteromonas hominis içeren preparatlar ele alındığında, fiksatif-1, fiksatif-2 ve klasik yöntemin benzer etkinlikte olduğunu fakat fiksatif-2'nin trofozoit formlarda, klasik yöntemin de kist formlarında parazitin morfolojik netliği ile parazitin dışkıdaki artefaktların arasında fark edilebilirliği açısından minimal bir üstünlüğü olduğu gözlenmiştir (Resim $4 a, b, c, d, e, f$ ).

lodamoeba bütschlii içeren preparatlar ele alındığında, fiksatif-2 ile klasik yöntemin benzer etkinlikte olduğu ve fiksatif-1'e kıyasla parazitin morfolojik netliği ile parazitin dışkıdaki artefaktların arasında fark edilebilirliği açısından daha üstün olduğu gözlenmiştir (Resim 5a,b,c,d,e,f). 


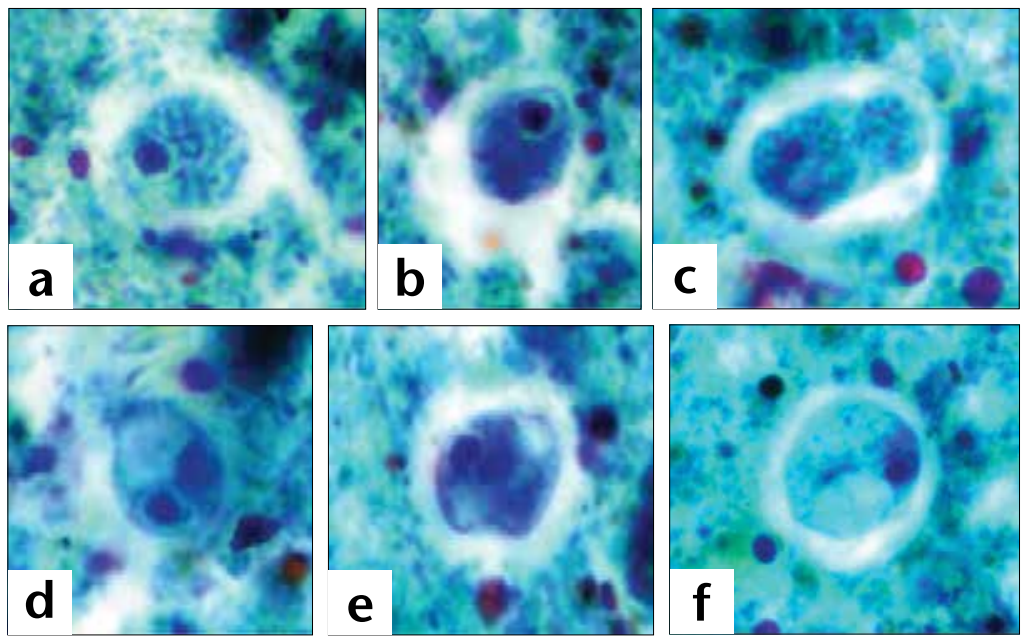

Resim 5. a. Fiksatif-1, I.bütschlii (trofozoit), b. Fiksatif-2, I.bütschlii (trofozoit), c. Schaudinn fiksatifi, I.bütschlii (trofozoit), d. Fiksatif-1, I.bütschlii (kist), e. Fiksatif-2, I. bütschlii (kist), f. Schaudinn fiksatifi, I.bütschlii (kist).

Chilomastix mesnili içeren preparatlar ele alındığında, fiksatif-1 ile fiksatif-2'nin benzer etkinlikte olduğu ve klasik yönteme kıyasla parazitin morfolojik netliği ile parazitin dışkıdaki artefaktların arasında fark edilebilirliği açısından minimal bir üstünlüğü olduğu gözlenmiştir (Resim 6a,b,c,d,e,f).
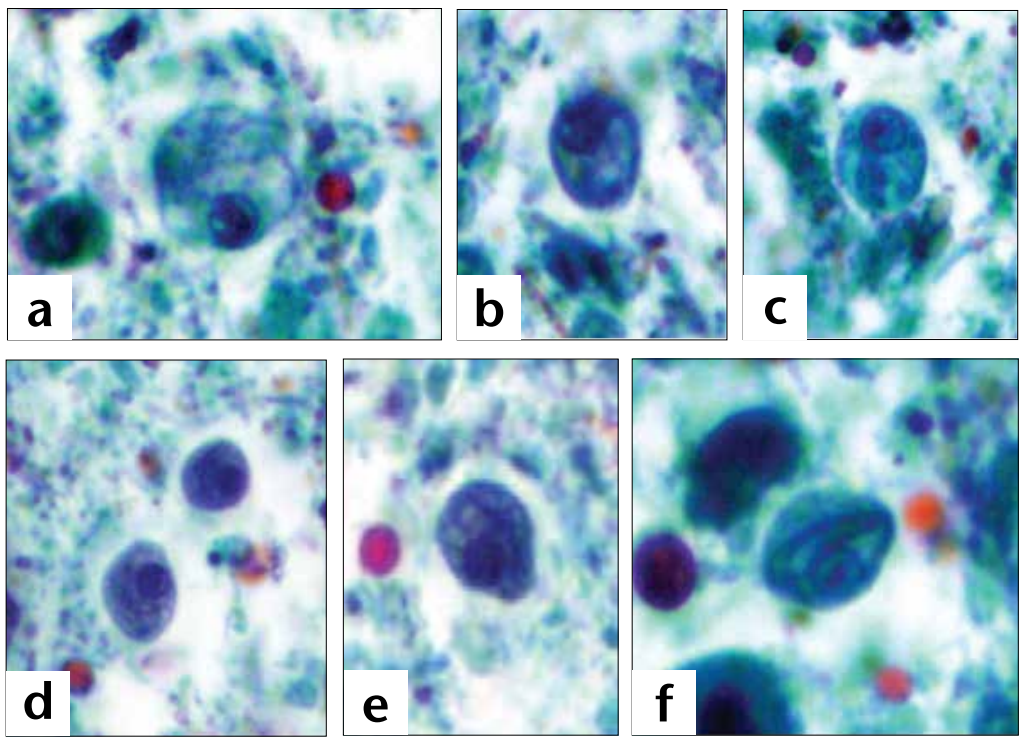

Resim 6. a. Fiksatif-1, C.mesnili (trofozoit), b. Fiksatif-2, C.mesnili (trofozoit), c. Schaudinn fiksatifi, C.mesnili (trofozoit), d. Fiksatif-1, C.mesnili (kist), e. Fiksatif-2, C. mesnili (kist), f. Schaudinn fiksatifi, C.mesnili (kist). 

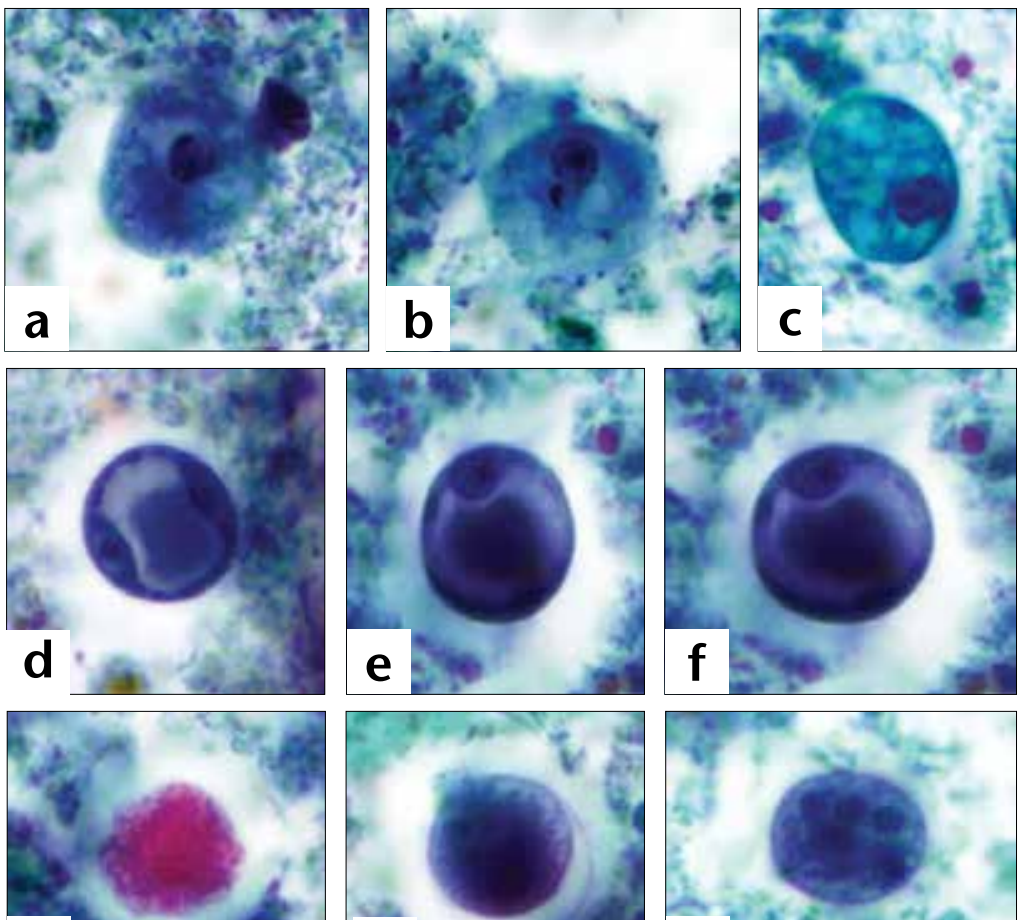

g
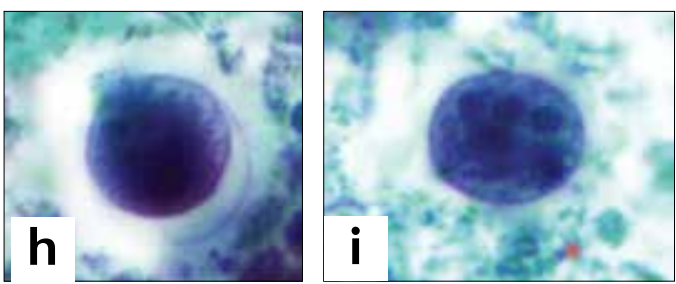

Resim 7. a. Fiksatif-1, E.coli (trofozoit), b. Fiksatif-2, E.coli (trofozoit), c. Schaudinn fiksatifi, E.coli (trofozoit), d. Fiksatif-1, E.coli (prekist), e. Fiksatif-2, E.coli (prekist), f. Schaudinn fiksatifi, E.coli (prekist), g. Fiksatif-1, E.coli (kist), h. Fiksatif-2, E.coli (kist), i. Schaudinn fiksatifi, E.coli (kist).

E.coli içeren preparatlar ele alındığında, klasik yöntemin fiksatif-1 ile fiksatif-2'ye kıyasla parazitin morfolojik netliği ile parazitin dışkıdaki artefaktların arasında fark edilebilirliği açısından daha üstün olduğu gözlenmiştir. Trofozoit ve prekistik formlarda her üç yöntem de benzer etkinlik gösterirken kistik formlarda klasik yöntemin çok net üstünlüğü görülmüştür (Resim 7a,b,c,d,e,f,g,h,i).

E.hartmanni içeren preparatlar ele alındığında, parazitin morfolojik netliği ile parazitin dışkıdaki artefaktların arasında fark edilebilirliği açısından sırası ile en üstün olanın klasik yöntem, sonrasında fiksatif-2, en son olarak da fiksatif-1 olduğu gözlenmiştir (Resim $8 a, b, c, d, e, f, g, h, i)$.

Giardia intestinalis içeren preparatlar ele alındığında, klasik yöntemin fiksatif-1 ile fiksatif-2'ye kıyasla parazitin morfolojik netliği ile parazitin dışıdaki artefaktların arasında fark edilebilirliği açısından bir miktar üstün olduğu gözlenmiştir. İncelenen preparatların tümü kist formlarını içermekteydi (Resim 9a,b,c). 

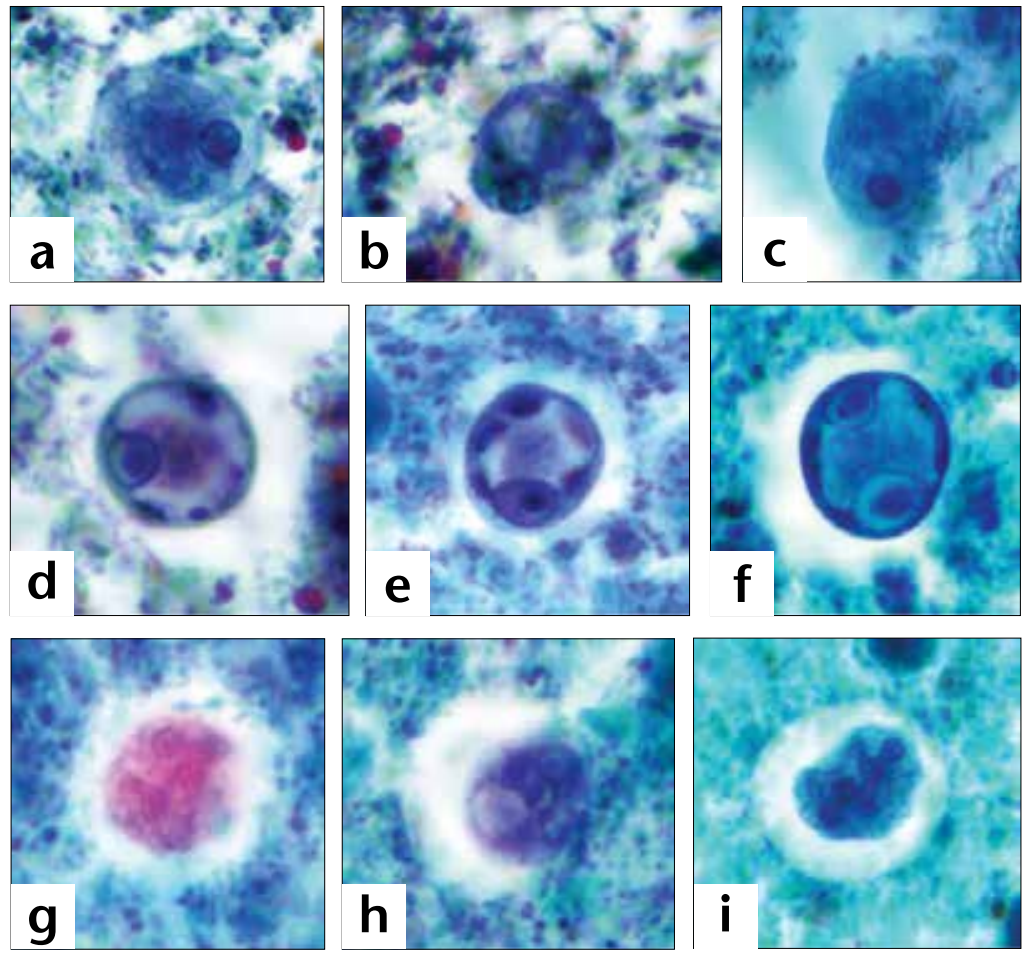

Resim 8. a. Fiksatif-1, E.hartmannii (trofozoit), b. Fiksatif-2, E.hartmanni (trofozoit), c. Schaudinn fiksatifi, E.hartmanni (trofozoit), d. Fiksatif-1, E.hartmanni (prekist), e. Fiksatif-2, E.hartmanni (prekist), f. Schaudinn fiksatifi, E.hartmanni (prekist), g. Fiksatif-1, E.hartmanni (kist), h. Fiksatif-2, E.hartmanni (kist), i. Schaudinn fiksatifi, E.hartmanni (kist).
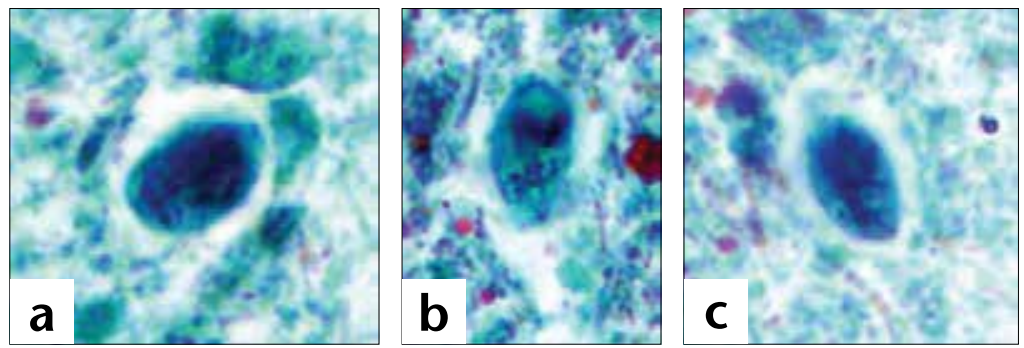

Resim 9. a. Fiksatif-1, G.intestinalis (kist), b. Fiksatif-2, G.intestinalis (kist), c. Schaudinn fiksatifi, G.intestinalis (kist).

Bu çalışma, taze dışkı preparatlarının numunenin kabulünden sonra çok kısa bir süre içinde incelenmesi sonucu tespit edilmesinin morfolojik anlamda fayda sağladığını göstermiştir. Özellikle dışkının bekletilmesi ile nem ve sıcaklık değişimine bağlı olarak trofozoit formundan kist formuna hızlı değişim gösteren E.nana ve C.mesnili gibi parazitlerin boyalı preparatlarında, sitoplazmik organellerin ve çekirdek yapılarının tam şekillenmemiş olduğu ara formların minimalize edilme şansı doğmuştur. 
Yöntemler kıyaslandığında, alternatif yöntemlerden fiksatif-1 ile hazırlanan preparatlar klasik yöntem kullanılarak hazırlanan preparatlara kıyasla, E.coli kistleri içerenlerde çok net olmak üzere Blastocystis spp., E.nana, I.bütschlii ve E.hartmanni içeren preparatlarda daha düşük bir performans sergilerken, D.fragilis içeren preparatlarda daha üstün bir performans sergilemiştir.

Fiksatif-2 ile yapılan preparatlar ise (E.coli kistleri içerenler dışında) klasik yöntem kullanılarak hazırlanan preparatlara hemen hemen yakın sonuçlar verirken, D.fragilis içeren preparatlarda daha üstün bir performans sergilemiştir.

Her iki alternatif yöntem kendi aralarında kıyaslandığında, fiksatif-2 ile hazırlanan preparatlar Blastocystis spp., E.nana, I.bütschlii ve E.hartmanni açısından kıstas alınan kriterler bazında daha iyi performans sergilerken, fiksatif- 1 D.fragilis içeren preparatlarda minimal bir üstünlük sergilemiştir.

Klasik yönteme kıyasla her iki alternatif yöntem de yaklaşık on katlık bir süre avantajı sağlamıştır.

\section{TARTIŞMA}

Altın standart olmasına rağmen toksik içeriğinden $\left(\mathrm{HgCl}_{2}\right)$, hem çalışan güvenliği hem de kimyasal atık olarak bertaraf edilmesindeki zorluklar ve bu durumun oluşturacağı olumsuz çevresel etkilerden dolayı araştırmacılar önceliği alternatif mordanlara ve farklı çözeltilere vermiştir ${ }^{4-8}$. Uygulayıcılar için bir başka dezavantaj olan sürecin uzunluğu ise öncelikli olarak ele alınmamıştır.

Bu uzun süreç, rutin laboratuvarlarda teknisyenlerin sayıca azlığı ve yeterli deneyime sahip olmamasından dolayı, çoğu kez sadece sulu dışkılarda boyama yönteminin kullanılmasına veya yöntemin hiç uygulanmamasına yol açmaktadır. Klasik yöntemi kullanan laboratuvarlar ise yoğun çalışma tempolarında ya da toplum taraması gerektiren yüksek sayılı örneklemelerde fiksasyon ve boyama süresinin uzun oluşunun dezavantajlarını yaşamaktadır².

Horen ${ }^{4}$, içerdiği toksik $\mathrm{HgCl}_{2}$ yüzünden Schaudinn çözeltisini modifiye etmek istemiş ve alternatif olarak bakır sülfat pentahidrat $\left(\mathrm{CuSO}_{4} \cdot 5 \mathrm{H}_{2} \mathrm{O}\right)$, kobalt klorit hekzahidrat $\left(\mathrm{CoCl}_{2} \times 6 \mathrm{H}_{2} \mathrm{O}\right)$, kobalt nitrat hekzahidrat $\left(\mathrm{Co}\left[\mathrm{NO}_{3}\right]_{2} \times{ }_{6} \mathrm{H}_{2} \mathrm{O}\right)$ ve ferrik klorür $\left(\mathrm{FeCl}_{3} \times{ }_{6} \mathrm{H}_{2} \mathrm{O}\right)$ adlı katyonları kullanmıştır. Yüzden fazla dışkı örneğinden hazırlanan preparatlarda, $\mathrm{CuSO}_{4} \times 5 \mathrm{H}_{2} \mathrm{O}$ içeren ve klasik Schaudinn fiksatifi ile fikse edilen örneklerde tatmin edici sonuçlar alınmış, protozoonların sitoplazmik ve çekirdek morfolojik karakterlerinin her iki yöntemde de birbiriyle kıyaslanabilir olduğu belirtilmiştir.

Garcia ve arkadaşları yapmış oldukları çalışmada ${ }^{5}, \mathrm{CuSO}_{4}$ içeren PVA fiksatifi ile geleneksel $\mathrm{HgCl}_{2}$ içeren PVA'yı kıyaslamışlardır. Özellikle trofozoit formlarında olmak üzere, her ne kadar en iyi çekirdek ve sitoplazmik ayrıntılar $\mathrm{HgCl}_{2}$ ile net sağlansa da, patojen türlerin cinsine bağlı olarak eşit morfolojik kıyaslamalar da elde etmiştir. Patojenik olmayan türlerde cins farklıııklarına bağlı olarak oranlar değişse de, bazılarında $\mathrm{CuSO}_{4}$ ile daha 
iyi morfolojiler elde edilmesine rağmen $\mathrm{HgCl}_{2}$ ile tümünde daha iyi sonuçlar elde edilmiştir. Kapsamlı bir şekilde bakıldığında, $\mathrm{CuSO}_{4}$ ile yapılan fiksasyonu ayrıntılardaki donukluk, büzüşme ve çekirdek detaylarındaki zayıf ayrımdan dolayı yetersiz bulmuşlardır.

Garcia ve arkadaşları yapmış oldukları bir başka çalışmada ${ }^{6}$, çinko sülfat $\left(\mathrm{ZnSO}_{4}\right)$ ve civa klorür $\mathrm{HgCl}_{2}$ içeren PVA fiksatiflerinin etkinliğini kıyaslamışlardır. Her ne kadar sayısal anlamda nadir protozoon içeren bazı preparatlarda etkeni atlamış, netlik ve çekirdek/ sitoplazma ayrıntıları açısından daha kötü bir performans sergilemiş, morfolojik ayrımda en çok E.nana'da zorlanmış, renk olarak daha yeşile çalmış olsa da $\mathrm{ZnSO}_{4}{ }^{\prime}$ ın protozoonları tanımlamada alternatif bir mordan olabileceğini belirtmişlerdir.

Garcia ve Shimizu yapmış oldukları bir diğer çalışmada ${ }^{7}$ ise, bağırsak paraziti tespit edilen 46 hastadaki 67 protozoonun tanımlaması amacıyla Ecofix ile fikse edilen preparatları, önerilen boya Ecostain (ES) ve Gomori'nin trikrom boyasının Wheatley modifikasyonu (WT) ile boyamış ve bu iki boyama yöntemini birbiriyle kıyaslamıştır. ES ve WT ile boyanan preparatlardaki protozoonların yapısal olarak karşılaştırılması sonucunda; olguların çoğu [36/67 (\%53.7)] eşit düzeyde, bazı olguların [24/67 (\%35.8)] ise ES boyamada, çok az bir kısmının [4/67 (\%6)] ise WT ile boyamada daha iyi olduğu tespit edilmiştir. Farklı fiksatif ve boya eşleştirmelerinin sağlayacağı uyumun klasik yönteme göre alternatif oluşturabileceğini belirtmişlerdir.

Nace ve arkadaşları yapmış oldukları bir çalışmada", "Strecktissue fixative (STF)" adında bir fiksatif ile $\mathrm{HgCl}_{4}$ bazlı PVA fiksatifi ve \%10'luk formalini karşılaştırmışlardır. Her ne kadar kalıc boyalı preparatlarda PVA'ya oranla keskinliğin kaybolması, çekirdek ve sitoplazmik ayrıntıların soyutlaşması ve renk tonunda kırmızı ve yeşile çalma gibi bulgular elde etmiş olsalar da STF'nin formalin ve toksik kimyasallar içermemesi, alkol bazlı olmaması, ileride trikrom boyama protokolünde basit bir takım değişiklikler yapılarak laboratuvarlar için güvenli bir alternatif olabileceğini belirtmişlerdir.

Jensen ve arkadaşları insan ve primatlardan aldıkları toplam 68 dışkıyı kullanarak yaptıkları çalışmada ${ }^{3}$, düşük viskoziteli PVA'ya alternatif olarak üç ticari fiksatifi (Ecofix, Parasafe ve Proto-fix) kullanarak hazırladıkları 272 kalıc boyalı preparatı karşılaştırmışlardır. Zemin ya da arka plan açısından Parasafe ile hazırlanan preparatlarda yaklaşık \%41 oranında kirlilik görülürken diğer üç fiksatifle hazırlanan preparatlarda bu görülmemiştir. Ayrıca, bu yöntemle en yüksek oranda parazitik şekil deformasyonu tespit edilmiştir. Dört farklı yöntemin beş parazitin (E.histolytica/dispar, E.coli, I.bütschlii, B.hominis, C.mesnili) tespit edilmesindeki duyarlılıkları istatistiksel anlamda değerlendirildiğinde, Protofix'in E.histolytica/dispar ve C.mesnili'nin tanımlanmasında PVA'dan daha iyi, diğer parazitlerin tanımlanmasında ise kıyaslanabilir olduğunu belirtmişlerdir. Tanımlamada Ecofix'in PVA ile benzer olduğu fakat netlik ve çekirdek/sitoplazma ayrıntıları açısından daha kötü bir performans sergilediği izlenmiştir. Parasafe'te ise, B.hominis, E.coli ve C.mesnili tanımlanması diğer üç yöntemin tümünden daha kötü sonuçlanırken, E.histolytica/dispar içeren hiçbir preparat tanımlanamamıştır. 
Pietrzak-Johnston ve arkadaşları ${ }^{8}$, düşük viskoziteli PVA'ya alternatif olarak beş ticari fiksatifi [(Ecofix, sodyum asetat-asetik asit-formalin (SAF), STF, Parasafe ve Proto-fix] kalıcı boyalı preparatların hazırlanmasında karşılaştırmışlardır. Ecofix dışındaki ticari kitler ile yapılan direkt ya da yoğunlaştırılmış kalıcı preparatların, düşük viskoziteli PVA ile fikse edilmiş preparatlardaki boyama kalitesine kıyasla daha donuk, soluk ve morfolojik detaylar açısından yetersiz kaldığı gözlemlenmiştir. Parasafe, STF ve bazen Proto-fix ve SAF ile fikse edilen preparatlarda amipler (E.histolytica/E.dispar, E.coli ve E.nana) zayıf korumalarına bağlı olarak en zor tanımlananlar olmuşlardır. Ecofix ile fikse edilen preparatların da önerilen boya (Ecostain) ile boyandığı takdirde düşük viskoziteli PVA ile fikse edilmiş preparatlardaki boyama kalitesine benzer sonuçlar gösterdiği belirtilmiştir.

Öncel'in yapmış olduğu çalışmada ${ }^{2}, 50$ adet taze dışkı örneği çinko sülfat hidrat $\left(\mathrm{ZnSO}_{4} \times 7 \mathrm{H}_{2} \mathrm{O}\right)$, bakır sülfat hidrat $\left(\mathrm{CuSO}_{4} \times 5 \mathrm{H}_{2} \mathrm{O}\right)$, alüminyum sülfat hidrat $\left[\mathrm{Al}_{2}\left(\mathrm{SO}_{4}\right)_{3} \times \mathrm{H}_{2} \mathrm{O}\right]$ ve ferrik sülfat hidrat $\left[\mathrm{Fe}_{2}\left(\mathrm{SO}_{4}\right)_{3} \times \mathrm{H}_{2} \mathrm{O}\right]$ gibi dört farklı mordan kullanılarak hazırlanmış etil alkol, formalin, asetik asit ve distile su bazlı fiksatifler ile tespit edilmiş preparatlar Gomori'nin trikrom boyasının modifiye edilmiş şekli (alternatif yöntem) ile boyanmıştır. Kontrol ve kıyaslama amacıyla altın standart olarak; cıva klorür içeren Schaudinn fiksatifi ile fikse edilen örnekler Gomori'nin trikrom boyasının Wheatley modifikasyonu (klasik yöntem) ile boyanmıştır. D.fragilis, E.histolytica/dispar ve E.coli trofozoitleri içeren preparatlar hemen hemen klasik yönteme benzer kriterlerde boyanmıştır. Blastocystis spp. ve G.intestinalis kistlerinde ise klasik yöntemin biraz daha üstün olduğu görülmüştür. Preparatlarda E.nana, E.coli, C.mesnili, E.hartmanni, I.bütschlii kist veya trofozoitleri de tiplendirilebilmiştir. Klasik yöntem kadar etkili olamadığı E.coli, C.mesnili, E.hartmanni, I.bütschlii kistleri ile ilgili olarak, nativ-lugol incelemesinde tipik ayırt edici morfolojileri ile tiplendirme için neredeyse boyamaya bile gereksinim duyulmamasının yöntem için bir dezavantaj olmayacağını belirtmiştir. Alternatif yöntemler ile yaklaşık beş dakika süren fiksasyon ve boyama sürecinin klasik yöntem ile yaklaşık 60-70 dakika olduğu ve bu sayede on kat daha hızı bir şekilde sonuca gidilebildiği belirtilmiştir.

Genel anlamda önceki yapılan çalışmalara bakıldığında, alternatif olarak sunulan yöntemlerde sürece vurgu yaparak, süreci kısaltma konusunda Öncel'in yaptığı çalışma ${ }^{2}$ dışında bir çözüm önerisi sunulmadığı görülmektedir. Jensen ve arkadaşları çalışmalarında ${ }^{3}$, Ecofix, Parasafe ve Proto-fix gibi ticari kitlerin uygulama aşamalarının 15 ile 22 basamak arasında olduğunu, boyalı preparatın hazır hale gelmesi için 24 ile 55 dakika arasında bir sürenin gerektiğini belirtmişlerdir. Pietrzak-Johnston ve arkadaşları ${ }^{8}$, Ecofix ve Proto-fix gibi ticari kitlerin yaklaşık 15 dakika gibi en kısa süreli boyama işlemine sahip olduğunu belirtmişlerdir. Iki çalışmada da aynı ticari kitler kullanılmasına rağmen, boyama süreleri farklı belirtilmiştir. Bu çalışmalarda ticari kitlerin alkol bazlı olmadığı, formaldehit ve özellikle $\mathrm{HgCl}_{2}$ içermediği belirtilmiş, kullanıcı dostu olduğu vurgulanmıştır.

Çalışmamızda, alternatif yöntemlerden fiksatif-2 ile yapılan preparatlar (E.coli kistleri içerenler dışında) klasik yöntem kullanılarak hazırlanan preparatlara hemen hemen yakın sonuçlar vermiştir. Fiksatif-1 ile birlikte $D$.fragilis içeren preparatlarda klasik yönteme göre daha üstün bir performans sergilenmiş ve süreç yaklaşık on kat kısalmıştır. 
Sonuç olarak, çalışmamızda kullanmış olduğumuz fiksatif-2 ve modifiye edilmiş boyama yöntemi parazitoloji ve mikrobiyoloji laboratuvarlarında yapılmakta olan insan dışkısına ait parazitolojik tetkiklerde boya ile tanımlama sürecinde E.coli kistleri içerenler dışında klasik yönteme kıyasla on kat daha hızlı tanımlamaya olanak sağladığı gibi yüksek toksik etkili $\mathrm{HgCl}_{2}$ de içermemektedir. Rutin kullanımda klasik yönteme iyi bir alternatif olabileceği düşünülmüş̧tür. Çalışma sürecinde görülmeyen birkaç parazitin de dahil edilmesi ile birlikte yapılacak olan çalışmaların bize yöntemin etkinliği ile ilgili daha kapsamlı bilgiler vereceği düşünülmektedir.

\section{Teşekkür}

Bu araştırmanın hazırlanma aşamasında, boyalı preparatların fotoğraflanmasında teknik alt yapı imkanlarını sunarak yardımlarını esirgemeyen Harran Üniversitesi Tıp Fakültesi, Tıbbi Patoloji Anabilim Dalı Öğretim Üyesi Anabilim Dalı Başkanı Prof. Dr. Muhammed Emin Güldür'e teşekkürlerimi sunarım.

\section{ÇIKAR ÇATIŞMASI}

Yazar bu makale ile ilgili herhangi bir çıkar çatışması bildirmemiştir.

\section{KAYNAKLAR}

1. Limoncu ME, Ok ÜZ. Taze dışkı örneğinin toplanması tespit edilmesi ve nakli, pp: 9-16. In: Korkmaz M, Ok UZ (eds), Parazitolojide Laboratuvar, Yöntem-Yorum-Akreditasyon. 2011. Meta Basım, İzmir.

2. Öncel K. Direkt bakıda tanımlama zorluğu yaşanılan dört parazit için alternatif bir yaklaşım. Türkiye Parazitol Derg 2018;42(4):268-76.

3. Jensen B, Kepley W, Guarner J, Anderson K, Anderson D, Clairmont J, et al. Comparison of polyvinyl alcohol fixative with three less hazardous fixatives for detection and identification of intestinal parasites. J Clin Microbiol 2000;38(4):1592-8.

4. Horen W.P. Modification of Schaudinn fixative. J Clin Microbiol 1981;13(1):204-5.

5. Garcia LS, Shimizu RY, Brewer TC, Bruckner DA. Evaluation of intestinal parasite morphology in polyvinylalcohol preservative: comparison of coppersulfate and mercuricchloride base for use in Schaudinn's fixative. J Clin Microbiol 1983;17(6):1092-5.

6. Garcia LS, Shimizu RY, Shum A, Bruckner DA. Evaluation of intestinal protozoan morphology in polyvinylalcohol preservative: comparison of zincsulfate- and mercuricchloride-based compounds for use in Schaudinn's fixative. J Clin Microbiol 1993;31(2):307-10.

7. Garcia LS, Shimizu RY. Evaluation of intestinal protozoan morphology in human fecal specimens preserved in Ecofix: comparison of Wheatley's trichrome stain and Ecostain. J Clin Microbiol 1998;36(7):1974-6.

8. Pietrzak-Johnston SM, Bishop H, Wahlquist S, Moura H, De Oliveira Da Silva N, Pereira Da Silva S, et al. Evaluation of commercially available preservatives for laboratory detection of helminths and protozoa in human fecal specimens. J Clin Microbiol 2000;38(5):1959-64.

9. Nace EK, Steurer FJ, Eberhard ML. Evaluation of streck tissue fixative, a non formalin fixative for preservation of stool samples and subsequent parasitologic examination. J Clin Microbiol 1999;37(12):4113-9.

10. Girginkardeşler N, Ok ÜZ. Kalıcı boyalı yaymalar, pp: 29-35. In: Korkmaz M, Ok UZ (eds), Parazitolojide Laboratuvar, Yöntem-Yorum-Akreditasyon. 2011. Meta Basım, İzmir. 